\title{
AVALIAÇÃO DA TRANSPOSIÇÃO DE SERAPILHEIRA E DO BANCO DE SEMENTES DO SOLO EM UMA ÁREA DEGRADADA NO PLANALTO CATARINENSE
}

\author{
Daiany Augusta Paes Martins ${ }^{1 *}$, Ana Carla Lanzarini ${ }^{2}$, Carine Farias Heinz ${ }^{2}$, Francielle Santos Vieira ${ }^{2}$, \\ Rafael Angelo Bonatto ${ }^{2}$, Maria Raquel Kanieski ${ }^{3}$ \\ 1* Universidade do Estado de Santa Catarina, Programa de Pós-Graduação em Engenharia Florestal, Lages, Santa Catarina, Brasil, - \\ *dapmflorestal@gmail.com \\ ${ }^{2}$ Universidade do Estado de Santa Catarina, Curso de Graduação, Lages, Santa Catarina, Brasil, - anacarlalanzarini@gmail.com; \\ heinz.carine@gmail.com; franviieira@gmail.com; rbonatto.florestal@gmail.com \\ ${ }^{3}$ Universidade do Estado de Santa Catarina, Departamento de Engenharia Florestal, Lages, Santa Catarina, Brasil - raquel.kanieski@udesc.br \\ Recebido para publicação: 08/05/2017 - Aceito para publicação: 21/09/2017
}

\begin{abstract}
Resumo
Este trabalho teve como objetivo avaliar a composição florística da transposição de serapilheira e do banco de sementes do solo de um fragmento florestal no município de Otacílio Costa, SC, com a finalidade de avaliar a viabilidade desse material para estimular a restauração florestal em áreas degradadas. Foram alocadas 22 parcelas de 3 m x 3 m em um fragmento de Floresta Ombrófila Mista e coletadas amostras da serapilheira e banco de sementes do solo a $5 \mathrm{~cm}$ de profundidade. Cada amostra foi homogeneizada e disposta em 22 parcelas de $1 \mathrm{~m}$ x $1 \mathrm{~m}$ em uma área degradada. As plântulas que emergiram com altura acima de $10 \mathrm{~cm}$ foram identificadas, contadas e plaqueteadas no momento de cada avaliação. A estrutura horizontal da comunidade foi avaliada por meio da densidade e frequência e a diversidade foi avaliada pelo índice de Shannon-Wiener (H') e equabilidade de Pielou (J). Foram identificadas 1527 plântulas, pertencentes a 59 espécies. As espécies que apresentaram maior densidade e frequência foram Mimosa scabrella e Mitracarpus hirtus. O índice de diversidade de Shannon-Wiener foi de 3,10 e o índice de equabilidade foi de 0,76. A transposição da serapilheira e do banco de sementes possibilitou a entrada de novas espécies na área, permitindo inferir que a metodologia adotada é promissora para estimular a restauração florestal em áreas degradadas.

Palavras-chave: Composição florística; restauração florestal; diversidade.
\end{abstract}

\begin{abstract}
Evaluation of the litter and soil seed bank transposition in a degraded area in the "Planalto Catarinense" region. This work aims to evaluate the floristic composition of the litter and soil seed bank transposition of a forest fragment in the city of Otacílio Costa, SC, in order to evaluate the viability of this material to stimulate forest restoration in degraded areas. Were allocated 22 plots with $3 \mathrm{~m} \times 3 \mathrm{~m}$ in an Araucaria Forest fragment and were collected samples from litter and soil seed bank at depth of $5 \mathrm{~cm}$. Each sample was homogenized and arranged in 22 plots of $1 \mathrm{~m} \times 1 \mathrm{~m}$ in a degraded area. The seedlings emerged above $10 \mathrm{~cm}$ high were accounted for, identified and classified at the time of each evaluation. The horizontal structure of the community was evaluated by density and frequency and the diversity was evaluated using the ShannonWiener index $\left(\mathrm{H}^{\prime}\right)$ and Pielou index $(\mathrm{J})$. Were identified 1527 seedlings belonging to 59 species. The species with the highest density and frequency were Mimosa scabrella and Mitracarpus hirtus. The diversity with the Shannon-Wiener index was 3,10 and with the Pielou evenness was 0,76. The transposition of litter and seed bank allowed the entry of new species in the area, allowing to infer that the methodology adopted is promising to stimulate forest restoration in degraded areas.

Keywords: Floristic composition; forest restoration; diversity.
\end{abstract}

\section{INTRODUÇÃO}

A Floresta com Araucária é uma das principais formações florestais da região Sul do Brasil, de grande importância ecológica, sendo o habitat de várias espécies e exerce importantes funções ambientais, como a proteção do solo e recursos hídricos. Isto, entretanto, não foi suficiente para a sua preservação. Estima-se que seus remanescentes, nos estágios primários ou mesmo avançados, não perfazem mais de $0,7 \%$ da área original (KANIESKI et al., 2010).

No Planalto Catarinense são vários os fatores que contribuem para a degradação desta tipologia florestal, dentre eles a mineração de cascalho. A extração de cascalho vem aumentando em decorrência do FLORESTA, Curitiba, PR, v. 47, n. 3, p. 237 - 246, jul. / set. 2017 
plantio de florestas que durante seu ciclo depende de uma rede de estradas pavimentadas para o tráfego intenso e pesado de máquinas e caminhões. No entanto, estudos sobre a recuperação de áreas degradadas pela mineração de cascalho no Planalto Sul Catarinense são escassos, provavelmente porque o impacto é pontual e de pequena extensão, com período de extração em longo prazo ou devido às práticas de atividades clandestinas, o que constitui um crime ambiental.

Atualmente a nova tendência da recuperação de áreas que foram degradadas têm preconizado o manejo e a indução dos processos ecológicos, visando aproveitar ou estimular a capacidade de resiliência dos ecossistemas. Para isso, o conhecimento das comunidades colonizadoras de áreas degradadas, bem como da autoecologia das espécies que as compõem, é fundamental para a definição de metodologias de restauração (RODRIGUES; GANDOLFI, 1998).

Entre os modelos e técnicas de restauração ecológica baseada nesse paradigma contemporâneo de sucessão, merece destaque a transposição do banco de sementes do solo ou topsoil. O objetivo dessa técnica é o aproveitamento do potencial de resiliência (auto-regeneração) e da máxima quantidade e diversidade de material vegetal (propágulos e restos vegetais) disponível (MARTINS, 2012) em remanescentes ou fragmentos florestais.

O banco de sementes é composto pelas sementes viáveis, em estado de dormência primária ou secundária, presentes na superfície ou no interior do solo (HARPER, 1977), que juntamente com a serapilheira que o recobre, é um importante reservatório de sementes de espécies nativas, matéria orgânica, insetos, mesofauna e microfauna do solo, microrganismos e nutrientes (BRANCALION, 2015). Em razão disso, essa camada do solo apresenta potencial de uso na restauração florestal se transferida de um fragmento natural para uma área degradada, uma vez que está envolvida na restauração da riqueza de espécies e colonização do ambiente, usualmente realizada por espécies pioneiras.

Entretanto os benefícios obtidos com o uso da camada superficial de solo nas ações de restauração não se restringem ao aproveitamento das sementes presentes no solo. A rebrota de tocos, raízes e galhos também potencializa o recrutamento de espécies nativas após a transposição da camada superficial de solo para uma área em processo de restauração (BRANCALION, 2015).

Nesse contexto, o banco de sementes do solo, considerando sua composição florística e densidade, é um dos mais importantes indicadores para a restauração de ecossistemas (MARTINS, 2012), uma vez que, por meio da sua avaliação, relativamente rápida e de baixo custo financeiro, é possível definir estratégias para acelerar o processo de sucessão ecológica nas áreas em restauração.

Desta forma, esse estudo teve por objetivo avaliar a composição florística da transposição de serapilheira e do banco de sementes do solo de um fragmento florestal no município de Otacílio Costa (SC) com a finalidade de avaliar a viabilidade desse material para estimular a restauração florestal em áreas degradadas.

Espera-se que a técnica aplicada possa favorecer a formação de um novo banco de sementes no local aplicado, sendo um importante passo para a Restauração Florestal da área degradada.

\section{MATERIAL E MÉTODOS}

\section{Área de estudo}

O estudo foi conduzido em uma área degradada no Município de Otacílio Costa, Santa Catarina, situada entre as coordenadas $27^{\circ} 32^{\prime} 13^{\prime \prime} \mathrm{S}$ e $50^{\circ} 05^{\prime} 86^{\prime \prime} \mathrm{O}$ e altitude de $848 \mathrm{~m}$. O clima na região, segundo Alvares et al. (2014), é classificado como "Cfb", ou seja, clima temperado constantemente úmido, com verões frescos, não apresentando estação seca definida com temperatura média anual em torno de $17^{\circ} \mathrm{C}$. A precipitação pluviométrica total anual pode variar de $1.360 \mathrm{~mm}$ a $1.600 \mathrm{~mm}$, com geadas frequentes.

O solo é classificado como Cambissolo Húmico Alumínico, considerado como solo pouco profundo ou raso, com cores de bruno escuro a bruno avermelhado, argiloso e com horizonte B incipiente (EMBRAPA, 2013) e apresentam baixa fertilidade e alta pedregosidade.

A vegetação florestal predominante pertence à Floresta Ombrófila Mista, constituída de fragmentos de diferentes estágios sucessionais, resultantes dos diversos processos de uso antrópico, como o pastoreio de bovinos e o plantio da espécie exótica Pinus spp.

A área experimental situa-se próximo a uma cascalheira e foi degradada em função da abertura de estradas e era utilizada para manobrar maquinários em virtude da mineração de cascalho para a pavimentação de estradas florestais. O solo argiloso apresenta presença intensa de fragmentos de rocha (cascalho, matacão, etc) e compactação excessiva.

\section{Coleta e análise dos dados}

A coleta de amostras da serapilheira e do banco de sementes do solo foi realizada em uma única vez, em dezembro de 2015, em um fragmento florestal em estágio médio de sucessão com base no levantamento 
florístico realizado próximo à área de estudo. Foram alocadas 22 parcelas de $3 \mathrm{~m}$ x $3 \mathrm{~m}$ de forma sistemática distante cinco metros uma das outras. No centro de cada parcela com auxílio de um gabarito com dimensão de 1 $\mathrm{m} \times 1 \mathrm{~m}$ foram coletadas amostras de serapilheira e banco de sementes do solo a uma profundidade de $5,0 \mathrm{~cm}$ (Figura 1A). As amostras foram recolhidas e acondicionadas em sacos plásticos, etiquetadas e imediatamente transportadas e depositadas em 22 parcelas de $1 \mathrm{~m} \mathrm{x} 1 \mathrm{~m}$ delimitadas na área experimental a campo (Figura 1B).
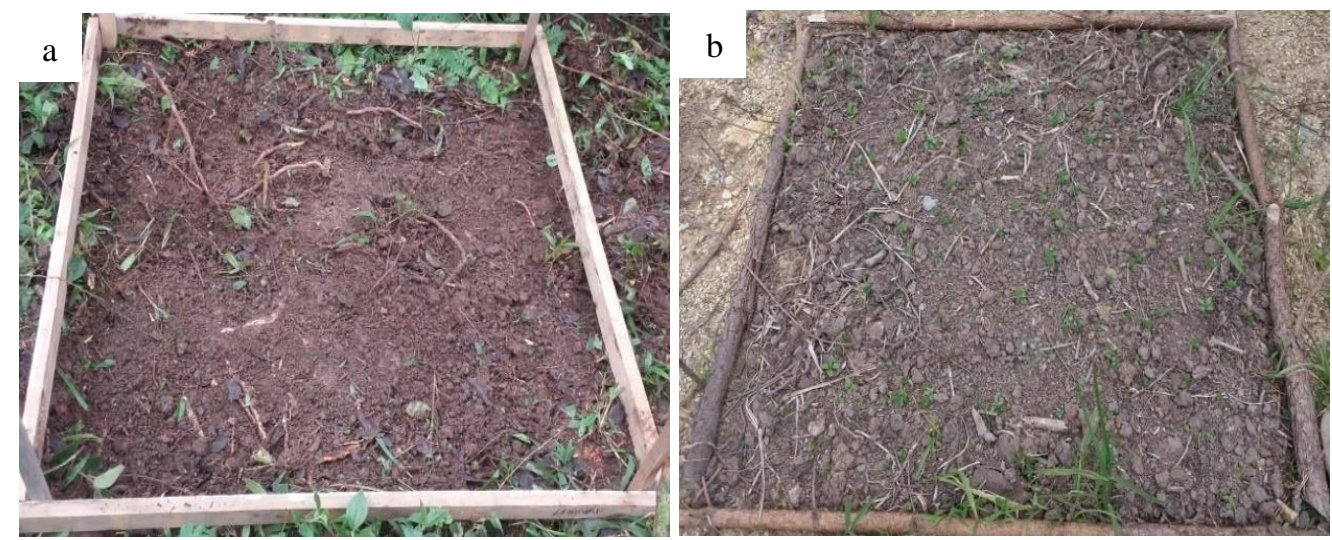

Figura 1. a) Coleta de serapilheira e do banco de sementes do solo no fragmento florestal; b) Deposição da serapilheira e do banco de sementes do solo na área experimental.

Figure 1. a) Collect of litter and soil seed bank in the forest fragment; b) Deposition of litter and soil seed bank in the experimental area.

O experimento foi conduzido por um período de dez meses, de janeiro a outubro de 2016. Trimestralmente todas as plântulas que emergiram com altura acima de $10 \mathrm{~cm}$ foram identificadas, contadas e plaqueteadas no momento de cada avaliação. A identificação das plantas foi realizada por meio de literatura específica e quando não foi possível conhecer a identidade do indivíduo regenerante a campo, este foi coletado e identificado por especialistas. Para a grafia dos nomes científicos e a autoria dos epítetos foram consultados os bancos de dados da Lista de Espécies da Flora do Brasil e o sistema de classificação do Angiosperm Phylogeny Group III (APG III, 2009). As espécies foram classificadas quanto à forma de vida (arbórea, arbustiva e herbácea), guilda de regeneração (pioneira, secundária inicial e secundária tardia) e síndrome de dispersão (anemocoria, autocoria e zoocoria).

Para analisar a estrutura horizontal da regeneração foram calculados os parâmetros fitossociológicos: densidade e frequência (absolutas e relativas). A avaliação de diversidade da composição florística foi feita pelo índice de Shannon-Wiener (H') e equabilidade de Pielou (J). A suficiência amostral foi elaborada por meio da curva de acumulação de espécies por meio do método de aleatorização, com 1.000 permutações. Todas as análises foram realizadas no programa estatístico R (R DEVELOPMENT CORE TEAM, 2016), junto com o pacote Vegan (OKSANEN et al., 2016) e por meio de planilha eletrônica.

\section{RESULTADOS}

Foram registradas 1527 plântulas, pertencentes a 16 famílias botânicas, 41 gêneros e 59 espécies, sendo destas três espécies não determinadas, distribuídas entre herbáceas, arbustivas e arbóreas (Figura 2a, 2b, 2c). A densidade encontrada foi de 64,4 plântulas por $\mathrm{m}^{2}$ (Tabela 1). 

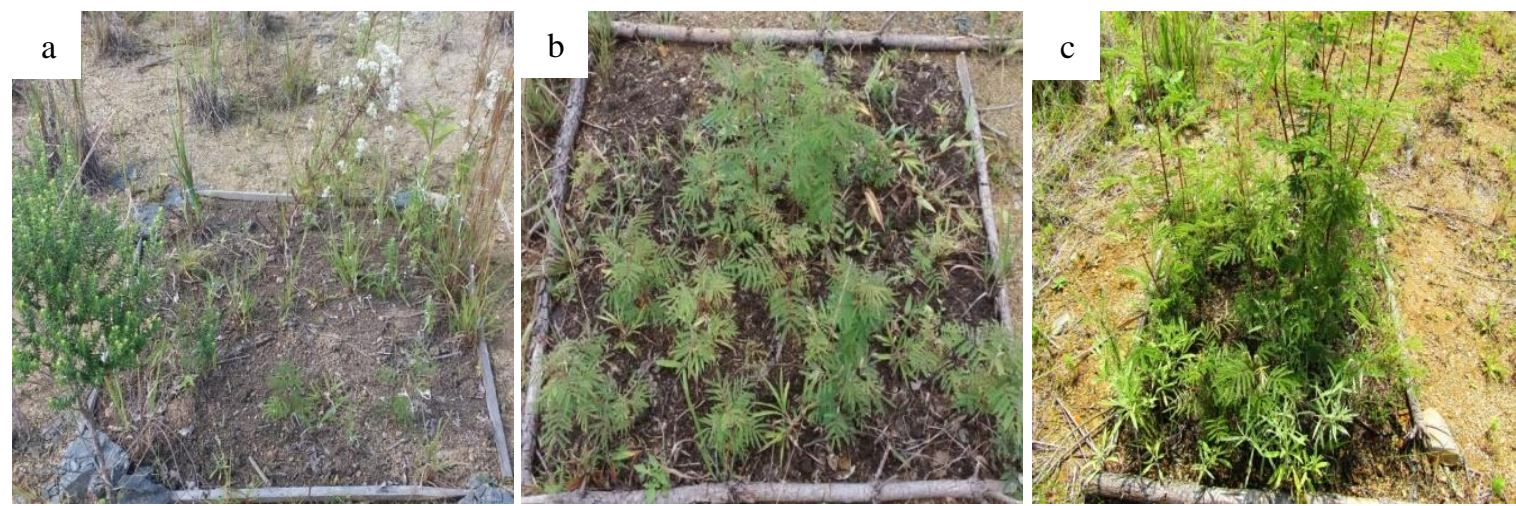

Figura 2. a) Plântulas emergidas na primeira avaliação; b) Plântulas emergidas na segunda avaliação; c) Plântulas emergidas na terceira avaliação na área experimental em Otacílio Costa (SC).

Figure 2. a) Seedlings emerged on first evaluation; b) Seedlings emerged in the second evaluation; c) Seedlings emerged in the third evaluation in the experimental area in Otacílio Costa (SC).

Tabela 1. Lista de espécies da transposição de serapilheira e do banco de sementes do solo de um fragmento de Florestal, em Otacílio Costa (SC).

Table 1. List of species of litter transposition and soil seed bank of a forest fragment in Otacílio Costa (SC).

\begin{tabular}{|c|c|c|c|c|c|c|c|c|}
\hline FAMÍLIA / ESPÉCIES & $\mathbf{N i}$ & FV & GR & SD & DA & DR & FA & FR \\
\hline APIACEAE & & & & & & & & \\
\hline Centella asiatica (L.) Urb. & 9 & $\mathrm{Hb}$ & $\mathrm{Si}$ & Auto & 0,41 & 0,59 & 18,18 & 1,80 \\
\hline $\begin{array}{l}\text { Ciclospermum leptophyllum (Pers.) } \\
\text { Sprague }\end{array}$ & 4 & $\mathrm{Hb}$ & $\mathrm{P}$ & Anemo & 0,18 & 0,26 & 4,55 & 0,45 \\
\hline $\begin{array}{l}\text { ASTERACEAE } \\
\text { Achyrocline satureioides (Lam.) DC. }\end{array}$ & 58 & $\mathrm{Hb}$ & $\mathrm{P}$ & Anemo & 2,64 & 3,80 & 40,91 & 4,05 \\
\hline Baccharis dracunculifolia DC. & 35 & Arb & $\mathrm{P}$ & Anemo & 1,59 & 2,29 & 13,64 & 1,35 \\
\hline Baccharis uncinella DC. & 44 & Arb & $\mathrm{P}$ & Anemo & 2,00 & 2,88 & 22,73 & 2,25 \\
\hline Baccharis trimera (Less.) DC. & 5 & Arb & $\mathrm{Si}$ & Anemo & 0,23 & 0,33 & 9,09 & 0,90 \\
\hline Baccharis cf. vulneraria Baker & 6 & Arb & $\mathrm{P}$ & Anemo & 0,27 & 0,39 & 45,45 & 4,50 \\
\hline Chaptalia nutans (L.) Pol. & 1 & $\mathrm{Hb}$ & St & Anemo & 0,05 & 0,07 & 4,55 & 0,05 \\
\hline Chevreulia sarmentosa (Pers.) Blake & 9 & $\mathrm{Hb}$ & $\mathrm{Si}$ & Anemo & 0,41 & 0,59 & 9,09 & 0,90 \\
\hline Conyza bonariensis (L.) Cronquist & 38 & $\mathrm{Hb}$ & $\mathrm{P}$ & Anemo & 1,73 & 2,49 & 22,73 & 2,25 \\
\hline Erechtites valerianifolius (Wolf) DC & 9 & $\mathrm{Hb}$ & $\mathrm{P}$ & Anemo & 0,41 & 0,59 & 9,09 & 0,90 \\
\hline Hypochaeris radicata $\mathrm{L}$. & 25 & $\mathrm{Hb}$ & $\mathrm{Si}$ & Anemo & 1,14 & 1,64 & 13,64 & 1,35 \\
\hline $\begin{array}{l}\text { Gamochaeta pensylvanica (Willd.) } \\
\text { Cabrera }\end{array}$ & 34 & $\mathrm{Hb}$ & $\mathrm{P}$ & Anemo & 1,55 & 2,23 & 31,82 & 3,15 \\
\hline Gamochaeta stachydifolia (Lam.) Cabrera & 14 & $\mathrm{Hb}$ & $\mathrm{P}$ & Anemo & 0,64 & 0,92 & 9,09 & 0,90 \\
\hline Senecio brasiliensis (Spreng.) Less. & 7 & Arb & $\mathrm{P}$ & Anemo & 0,32 & 0,46 & 13,64 & 1,35 \\
\hline Sonchus oleraceus L. & 1 & $\mathrm{Hb}$ & $\mathrm{P}$ & Anemo & 0,05 & 0,07 & 4,55 & 0,45 \\
\hline Vernonia sp. & 4 & Arb & $\mathrm{P}$ & Anemo & 0,18 & 0,26 & 4,55 & 0,45 \\
\hline $\begin{array}{l}\text { Vernonanthura sp. } \\
\text { COMMELINACEAE }\end{array}$ & 9 & Arb & $\mathrm{P}$ & Anemo & 0,41 & 0,59 & 18,18 & 1,80 \\
\hline $\begin{array}{l}\text { Commelina } \text { sp. } \\
\text { CYPERACEAE }\end{array}$ & 2 & $\mathrm{Hb}$ & $\mathrm{P}$ & $\mathrm{Nc}$ & 0,09 & 0,13 & 4,55 & 0,45 \\
\hline Bulbostylis capillaris (L.) C.B.Clarke & 12 & $\mathrm{Hb}$ & $\mathrm{P}$ & Anemo & 0,55 & 0,79 & 9,09 & 0,90 \\
\hline Cyperus odoratus $\mathrm{L}$. & 29 & $\mathrm{Hb}$ & $\mathrm{P}$ & Anemo & 1,32 & 1,90 & 22,73 & 2,25 \\
\hline Cyperus rigens C.Presl & 7 & $\mathrm{Hb}$ & $\mathrm{P}$ & Anemo & 0,32 & 0,46 & 4,55 & 0,45 \\
\hline Fimbristylis dichotoma (L.) Vahl & 13 & $\mathrm{Hb}$ & $\mathrm{P}$ & Auto & 0,59 & 0,85 & 13,64 & 1,35 \\
\hline Kyllinga brevifolia Rottb. & 15 & $\mathrm{Hb}$ & $\mathrm{P}$ & Auto & 0,68 & 0,98 & 54,55 & 5,41 \\
\hline $\begin{array}{l}\text { Rhynchospora barrosiana Guagl. } \\
\text { EUPHORBIACEAE }\end{array}$ & 8 & $\mathrm{Hb}$ & $\mathrm{P}$ & Auto & 0,36 & 0,52 & 9,09 & 0,90 \\
\hline Croton triqueter Lam. & 10 & Arb & $\mathrm{P}$ & Auto & 0,45 & 0,65 & 18,18 & 1,80 \\
\hline $\begin{array}{l}\text { Sapium glandulosum (L.) Morong } \\
\text { FABACEAE }\end{array}$ & 2 & Arv & $\mathrm{Si}$ & Auto & 0,09 & 0,13 & 4,55 & 0,45 \\
\hline Desmodium adscendens (Sw.) DC. & 3 & $\mathrm{Hb}$ & $\mathrm{Si}$ & Zoo & 0,14 & 0,20 & 4,55 & 0,45 \\
\hline Trifolium polymorphum Poir. & 8 & $\mathrm{Hb}$ & $\mathrm{P}$ & Auto & 0,36 & 0,52 & 13,64 & 1,35 \\
\hline
\end{tabular}




\begin{tabular}{|c|c|c|c|c|c|c|c|c|}
\hline $\begin{array}{l}\text { Mimosa scabrella } \text { Benth. } \\
\text { INDETERMINADA }\end{array}$ & 351 & Arv & $\mathrm{P}$ & Auto & 15,95 & 22,99 & 54,55 & 5,41 \\
\hline Indeterminada 1 & 5 & $\mathrm{Nc}$ & $\mathrm{Nc}$ & $\mathrm{Nc}$ & 0,23 & 0,33 & 13,64 & 1,35 \\
\hline Indeterminada 2 & 4 & $\mathrm{Nc}$ & $\mathrm{Nc}$ & $\mathrm{Nc}$ & 0,18 & 0,26 & 9,09 & 0,90 \\
\hline Indeterminada 3 & 11 & $\mathrm{Nc}$ & $\mathrm{Nc}$ & $\mathrm{Nc}$ & 0,50 & 0,72 & 18,18 & 1,80 \\
\hline $\begin{array}{l}\text { IRIDACEAE } \\
\text { Sisyrinchium cf. vaginatum }\end{array}$ & 26 & $\mathrm{Hb}$ & $\mathrm{P}$ & Auto & 1,18 & 1,70 & 13,64 & 1,35 \\
\hline $\begin{array}{l}\text { JUNCACEAE } \\
\text { Juncus microcephalus Kunth }\end{array}$ & 15 & $\mathrm{Hb}$ & $\mathrm{P}$ & Auto & 0,68 & 0,98 & 18,18 & 1,80 \\
\hline $\begin{array}{l}\text { LYTHRACEAE } \\
\text { Cuphea carthagenensis (Jacq.) J.Macbr. }\end{array}$ & 5 & $\mathrm{Hb}$ & $\mathrm{Si}$ & Zoo & 0,23 & 0,33 & 9,09 & 0,90 \\
\hline $\begin{array}{l}\text { MALVACEAE } \\
\text { Sida rhombifolia } \mathrm{L} \text {. }\end{array}$ & 38 & $\mathrm{Hb}$ & $\mathrm{Si}$ & Auto & 1,73 & 2,49 & 18,18 & 1,80 \\
\hline $\begin{array}{l}\text { POACEAE } \\
\text { Andropogon leucostachyus Kunth }\end{array}$ & 32 & $\mathrm{Hb}$ & $\mathrm{P}$ & Anemo & 1,45 & 2,10 & 18,18 & 1,80 \\
\hline Andropogon bicornis L. & 39 & $\mathrm{Hb}$ & $\mathrm{P}$ & Anemo & 1,77 & 2,55 & 22,73 & 2,25 \\
\hline Briza minor $\mathrm{L}$. & 10 & $\mathrm{Hb}$ & $\mathrm{P}$ & Anemo & 0,45 & 0,65 & 4,55 & 0,45 \\
\hline Cynodon dactylon (L.) Pers. & 18 & $\mathrm{Hb}$ & $\mathrm{P}$ & Auto & 0,82 & 1,18 & 27,27 & 2,70 \\
\hline Digitaria $\mathrm{sp} 1$ & 25 & $\mathrm{Hb}$ & $\mathrm{P}$ & Auto & 1,14 & 1,64 & 22,73 & 2,25 \\
\hline Digitaria $\mathrm{sp} 2$ & 14 & $\mathrm{Hb}$ & $\mathrm{P}$ & Auto & 0,64 & 0,92 & 22,73 & 2,25 \\
\hline Eragrostis polytricha Nees & 8 & $\mathrm{Hb}$ & $\mathrm{P}$ & Auto & 0,36 & 0,52 & 9,09 & 0,90 \\
\hline Eragrostis plana Nees & 47 & $\mathrm{Hb}$ & $\mathrm{P}$ & Auto & 2,14 & 3,08 & 54,55 & 5,41 \\
\hline Panicum sp. & 7 & $\mathrm{Hb}$ & $\mathrm{P}$ & Zoo & 0,32 & 0,46 & 4,55 & 0,45 \\
\hline Panicum sp.1 & 9 & $\mathrm{Hb}$ & $\mathrm{P}$ & Zoo & 0,41 & 0,59 & 9,09 & 0,90 \\
\hline Panicum sp.2 & 2 & $\mathrm{Hb}$ & $\mathrm{P}$ & Zoo & 0,09 & 0,13 & 9,09 & 0,90 \\
\hline Paspalum sp. & 27 & $\mathrm{Hb}$ & $\mathrm{P}$ & Auto & 1,23 & 1,77 & 9,09 & 0,90 \\
\hline Paspalum mandiocanum Trin. & 31 & $\mathrm{Hb}$ & $\mathrm{P}$ & Auto & 1,41 & 2,03 & 27,27 & 2,70 \\
\hline Paspalum dilatatum Poir. & 32 & $\mathrm{Hb}$ & $\mathrm{P}$ & Auto & 1,45 & 2,10 & 22,73 & 2,25 \\
\hline $\begin{array}{l}\text { PLANTAGINACEAE } \\
\text { Plantago tomentosa Lam. } \\
\text { RUBIACEAE }\end{array}$ & 1 & $\mathrm{Hb}$ & $\mathrm{P}$ & Zoo & 0,05 & 0,07 & 4,55 & 0,45 \\
\hline Mitracarpus hirtus (L.) DC. & 292 & $\mathrm{Hb}$ & $\mathrm{P}$ & Auto & 13,27 & 19,12 & 72,73 & 7,21 \\
\hline $\begin{array}{l}\text { Richardia brasiliensis Gomes } \\
\text { RUTACEAE }\end{array}$ & 20 & $\mathrm{Hb}$ & $\mathrm{P}$ & Zoo & 0,91 & 1,31 & 9,09 & 0,90 \\
\hline $\begin{array}{l}\text { Zanthoxylum rhoifolium Lam. } \\
\text { SOLANACEAE }\end{array}$ & 2 & Arv & $\mathrm{P}$ & Zoo & 0,09 & 0,13 & 4,55 & 0,45 \\
\hline Solanum americanum Mill. & 5 & Arb & $\mathrm{P}$ & Zoo & 0,23 & 0,33 & 4,55 & 0,45 \\
\hline Solanum mauritianum Scop. & 6 & Arb & $\mathrm{P}$ & Zoo & 0,27 & 0,39 & 9,09 & 0,90 \\
\hline $\begin{array}{l}\text { Solanum viarum Dunal } \\
\text { VIOLACEAE }\end{array}$ & 15 & Arb & $\mathrm{P}$ & Zoo & 0,68 & 0,98 & 22,73 & 2,25 \\
\hline Hybanthus communis (A.St.-Hil.) Taub. & 9 & $\mathrm{Hb}$ & $\mathrm{Si}$ & Auto & 0,41 & 0,59 & 9,09 & 0,90 \\
\hline Total & 1527 & & & & 69,4 & 100 & 1009,1 & 100 \\
\hline
\end{tabular}

A suficiência amostral foi satisfatória para quantificar a riqueza da área, pois tendeu à estabilidade (Figura 3). O valor obtido para o coeficiente angular da tangente no ponto da curva representado pela penúltima parcela (21) foi 0,47. Isto demonstra a necessidade de inclusão de pelo menos três parcelas para a amostragem de uma nova espécie, o que demonstra a adequabilidade do esforço amostral para a caracterização da composição florística da área. 


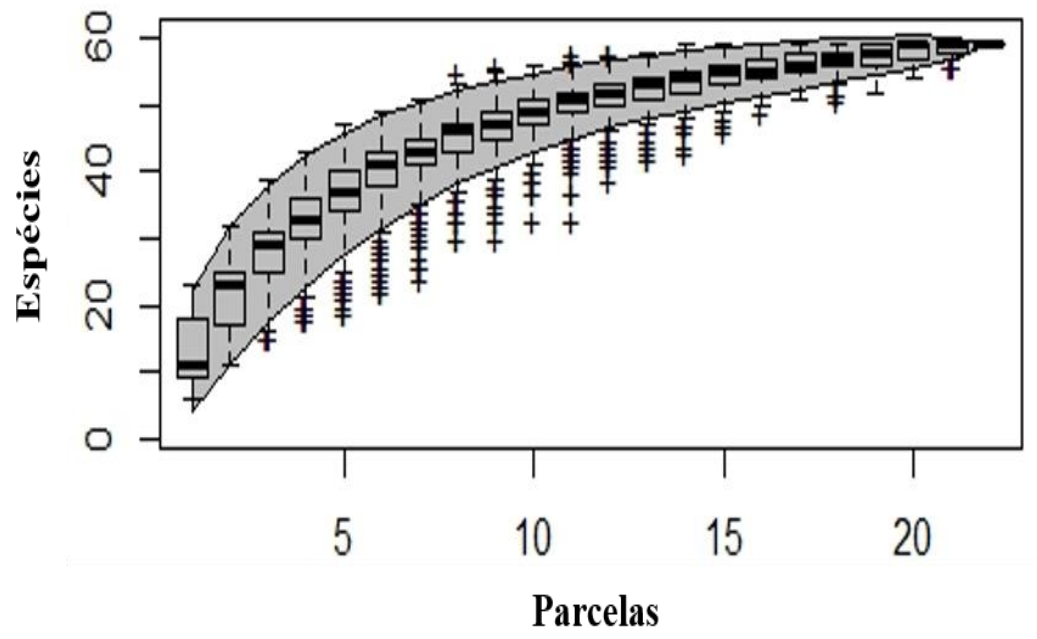

Figura 3. Curva de acumulação das espécies amostradas no banco de sementes do solo de um fragmento de florestal em Otacílio Costa (SC).

Figure 3. Accumulation curve of sampled species soil's seed bank of a fragment of forest in Otacílio Costa (SC).

Destacaram-se em abundância ao nível de famílias botânicas, Fabaceae (24\%), Rubiaceae (21\%), Poaceae (20\%) e Asteraceae (20\%). Com relação à riqueza de espécies as famílias Asteraceae (16), Poaceae (14) e Cyperaceae (seis) foram as mais representativas. Dessas plântulas amostradas, $66 \%$ correspondem às herbáceas (1006 plântulas), seguida de 23\% arbóreas (355 plântulas) e 10\% arbustivas (146 plântulas).

As espécies com maior densidade e frequência foram Mimosa scabrella com 351 plântulas, representando 98,8\% das plântulas arbóreas, seguida de Mitracarpus hirtus com 292 plântulas, representando 29\% das plântulas herbáceas e Baccharis uncinella com 58 plântulas, representando 40\% das plântulas arbustivas amostradas.

Entre as espécies arbóreas destacaram-se também Sapium glandulosum e Zanthoxylum rhoifolium. Das espécies herbáceas mais abundantes além de Mitracarpus hirtus, Achyrocline satureioides e Eragrostis plana foram as mais representativas. Enquanto que Baccharis uncinella e Baccharis dracunculifolia foram as espécies arbustivas mais abundantes. Os gêneros de maior riqueza de espécies foram Baccharis spp. (quatro), Solanum spp. (três), Panicum spp. (três) e Paspalum spp. (três).

Quanto à guilda de regeneração se observa que a quantidade de espécies com características de pioneiras compuseram $78 \%$, as secundárias iniciais $15 \%$ e as secundárias tardias $2 \%$. Em se tratando de síndrome de dispersão, a estratégia de dispersão por anemocoria (39\%) foi superior à autocórica (36\%) e zoocórica (19\%).

O valor do índice de diversidade de Shannon-Wiener (H') obtido para o presente estudo foi de 3,10 e a Equabilidade de Pielou (J') foi de 0,76.

\section{DISCUSSÃO}

O conjunto de famílias mais representativas neste estudo assemelha-se aos encontrados por Miranda Neto et al. (2010), em estudo da transposição do banco de sementes de uma Floresta Estacional Semidecidual, no qual obtiveram predominância de indivíduos da família botânica Fabaceae. Miranda Neto et al. (2017), em uma Florestal Estacional Semidecidual Montana obtiveram alta representatividade da família botânica Rubiaceae dentre as famílias encontradas no banco de sementes.

A família botânica Fabaceae é a reconhecida por estabelecer simbiose eficiente com bactérias fixadoras de $\mathrm{N}_{2}$ atmosférico, característica importante no processo de restauração florestal em solos de baixa fertilidade, como aqueles encontrados em áreas degradadas (CHADA et al., 2004). A família Rubiaceae exerce papel fundamental na recuperação de áreas degradadas, por ser fonte de recursos para os animais que se alimentam de seus frutos, sendo os morcegos, macacos e os pássaros alguns dos seus dispersores naturais.

As espécies das famílias Asteraceae (16), Poaceae (14) e Cyperaceae (seis) apresentaram alta representatividade por serem características de ambientes antropizados. A primeira pode ser encontrada em diversas formações vegetais, desde florestas secundárias maduras a ambientes perturbados ou degradados 
(PEREIRA et al., 2010). A segunda e a terceira estão associadas às florestas com indícios de perturbações recorrentes. Esse resultado corrobora com o estudo de Martins et al. (2008) em que as famílias com maior número de indivíduos no banco de sementes foram Asteraceae e Poaceae. Schorn, et al. (2013) também apontaram que as espécies com maior número de indivíduos foram Asteraceae $(28,1 \%)$ e Poaceae $(17,7 \%)$.

De acordo Zimmerman et al. (2000), essa vegetação atenua a temperatura do solo, interceptando a incidência solar direta, protege contra a erosão e fornece matéria orgânica para o início de uma pequena atividade microbiana de decomposição, promovendo assim uma atenuação dos fatores ecológicos físicos e um início do processo de interação biótica.

A maior proporção de espécies com hábito de vida herbáceo corrobora com o estudo realizado por Rodrigues et al. (2010), em que a forma de vida mais representativa foi herbácea, seguida de arbórea e arbustiva. O predomínio de espécies herbáceas germinadas no banco de sementes do solo registradas neste estudo pode estar relacionado à matriz de inserção do fragmento florestal no qual foram coletadas as amostras, ao ciclo de vida dessas espécies, ao pequeno tamanho das sementes, aos mecanismos de dispersão, ausência de dossel e a camada de serapilheira, pois, além de suportarem condições adversas, sobrevivem tanto em ambientes secos como úmidos e são pouco exigentes quanto as condições edáficas.

As espécies com maior densidade e frequência neste estudo foram Mimosa scabrella, Mitracarpus hirtus e Baccharis uncinella. Miranda Neto et al. (2017) relata que a predominância de espécies pioneiras no banco de sementes, normalmente apresentam rápido crescimento a pleno sol, é um indicador de resiliência a perturbações naturais ou antrópicas.

M. scabrella é uma espécie pioneira de rápido crescimento e recobrimento do solo, apresenta interações com micro-organismos do solo, contribui com elevada produção de biomassa foliar incrementando a ciclagem de nutrientes favorecendo o desenvolvimento dos processos ecológicos envolvidos na sucessão florestal. Além de ser comumente encontrada em maior densidade no banco de sementes do solo, devido à grande produção e eficiente dispersão e dormência das sementes, reabilita solos degradados.

Mitracarpus hirtus é uma planta heliófita que não apresenta preferências por condições de solo, habita áreas abandonadas, cuja dispersão é autocórica. Baccharis uncinella é uma espécie arbustiva, pioneira de copa arredonda e folhas pequenas, encontrada na beira de estradas, áreas de baixo pastejo e nos campos de altitude. Apresenta rápido crescimento a pleno sol e é uma indicadora de que mesmo diante da ocorrência de perturbações naturais ou antrópicas o ecossistema possui condições favoráveis à regeneração.

A elevada riqueza de gêneros como Baccharis, indica o caráter inicial do processo de restauração, pois eles apresentam, em geral, espécies que preferem áreas abertas ou florestas alteradas, nas quais existe maior incidência de luz (RECH et al., 2015). O gênero Solanum é representado por ervas e arbustos comuns em matas secundárias, capoeiras e ambientes perturbados. A dispersão predominante é a zoocoria principalmente por aves e morcegos, enquanto que os gêneros Panicum e Paspalum compreendem plantas forrageiras agressivas com ampla adaptabilidade em ambientes antropizados cujas sementes são disseminadas por animais e pelo vento.

O predomínio de espécies pioneiras em banco de sementes do solo também foi observado por Capellesso et al. (2015), evidenciando sua contribuição na restauração florestal, visto que auxiliam na regeneração das florestas, garantindo a sua resiliência, atuando no processo de sucessão florestal após distúrbios naturais ou antrópicos (Martins et al., 2012). No entanto, apesar da baixa proporção de espécies secundárias, essas caracterizam o avanço gradual do processo sucessional, bem como a redução da participação de espécies pioneiras.

A síndrome de dispersão por anemocoria apresentou maior proporção de espécies confirmando a importância desta síndrome na colonização de áreas abertas, já que espécies anemocóricas em geral são pioneiras, de ambientes secos facilmente dispersas pelo vento. A principal representante desta síndrome de dispersão foi à família Asteraceae.

Analisando o índice de Shannon-Wiener e a equabilidade de Pielou verificou-se que a área apresenta uma diversidade média com distribuição florística heterogênea, indicando baixa dominância ecológica e distribuição mais uniforme das plântulas regenerantes entre as espécies. Os valores de H' e J encontrados no presente estudo foram superiores aos obtidos por Avila et al. (2011), em banco de sementes do solo em Floresta Ombrófila Mista.

Vários outros autores relatam resultados distintos para os índices de diversidade e equabilidade do banco de sementes do solo e, em geral estão relacionados com as diferentes fitofisionomias florestais e ao estágio de sucessão da vegetação (Tabela 2). Isso mostra que essas diferenças podem refletir a falta de padronização metodológica, o que limita comparações desses índices.

FLORESTA, Curitiba, PR, v. 47, n. 3, p. 237 - 246, jul. / set. 2017.

Martins, D. A. P. et al.

ISSN eletrônico 1982-4688

DOI: $10.5380 /$ rf.v47i1. 52237 
Tabela 2. Relação de estudos sobre diversidade (H') e equabilidade (J) utilizados na comparação entre a área do presente estudo e demais fitofisionomias florestais.

Table 2. List of studies on diversity and equability used in the comparison between the area of the present study and other forest physiognomy.

\begin{tabular}{|c|c|c|c|}
\hline AUTORES & FITOFISIONOMIA & SHANNON & PIELOU \\
\hline Pereira et al., 2010 & FESDM & 1,09 & 0,61 \\
\hline Avila et al., 2011 & FOM & 2,83 & 0,66 \\
\hline Schorn et al., 2013 & Transição FOM - FOD & 3,18 & 0,93 \\
\hline Miranda Neto et al., 2014 & FESD & 3,21 & 0,70 \\
\hline Capellesso et al., 2015 & Transição FOM - FESD & 2,34 & - \\
\hline Ribeiro et al., 2017 & $\mathrm{CH}$ & 2,22 & 0,64 \\
\hline Brandão et al., 2017 & FESDM & 1,96 & 0,60 \\
\hline
\end{tabular}

A riqueza de plântulas encontradas neste estudo sugere que o processo de restauração da área esteja ocorrendo de forma adequada, uma vez que em estágios iniciais de sucessão espera-se o aumento da diversidade, a partir do estabelecimento de novas espécies na área. $\mathrm{O}$ fato de a área ter sido isolada de distúrbios certamente contribui para a elevada diversidade relativa dos indivíduos regenerantes, o que demonstra que estes tipos de atividades conservacionistas são de grande importância para a restauração ecológica, quando se tem a presença de fontes de propágulos próximas (RECH et al., 2015), como é o caso deste estudo.

\section{CONCLUSÕES}

- Na composição da transposição de serapilheira e do banco de sementes do solo houve predomínio de espécies herbáceas pioneiras em sua maioria anemocóricas.

- As espécies Mimosa scabrella (arbórea) e Mitracarpus hirtus (herbácea) apresentaram maior densidade e frequência em relação às demais espécies encontradas. Os gêneros de maior riqueza de espécies foram Baccharis spp., Solanum spp., Panicum spp. e Paspalum spp.

- Verificou-se uma diversidade de espécies mediana na composição da transposição de serapilheira e do banco de sementes do solo evidenciando o avanço sucessional das espécies.

- A transposição da serapilheira e do banco de sementes possibilitou a entrada de novas espécies na área, permitindo inferir que a metodologia adotada é promissora para estimular a restauração florestal em áreas degradadas.

- Atualmente há uma carência de trabalhos publicados sobre a transposição de serapilheira e do banco de sementes do solo em Floresta Ombrófila Mista, assim, estudos semelhantes devem ser incentivados para fim de análises comparativas.

- Como ação para melhorar a área degradada em restauração e garantir a sua manutenção no tempo, recomenda-se o manejo das espécies da transposição de serapilheira e do banco de sementes do solo para que plantas herbáceas agressivas não inibam o desenvolvimento de outras espécies.

\section{AGRADECIMENTOS} (FAPESC).

A empresa Klabin S.A e a Fundação de Amparo à Pesquisa e Inovação do Estado de Santa Catarina

\section{REFERÊNCIAS}

ALVARES, C. A.; STAPE, J. L.; SENTELHAS, P. C.; DE MORAES GONÇALVES, J. L.; SPAROVEK, G. Köppen's climate classification map for Brazil. Meteorologische Zeitschrift, Stuttgart, v. 22, n. 6, p. 711-718, 2014.

AVILA, A. L.; ARAUJO, M. M.; LONGHI, S. J.; GASPARIN, E. Agrupamentos florísticos na regeneração natural em remanescente de Floresta Ombrófila Mista, RS, Brasil. Scientia Forestalis, Piracicaba, v. 39, n. 91, p. 331-342, 2011. 
APG III - Angiosperm Phylogeny Group III. An update of the Angiosperm Phylogeny Group classification for the orders and families of flowering plants. Botanical Journal of the Linnean Society, v. 161, n. 2, p. 105-121, 2009.

BRANCALION, P. H. S. Métodos de restauração florestal: áreas que não possibilitam o aproveitamento inicial da regeneração natural. In: BRANCALION, P. H. S. GANDOLFI, S.; RODRIGUES, R.R. Restauração Florestal. São Paulo: Oficina e Textos. p. 252-285. 2015.

BRANDÃO, J. F. C.; MARTINS, S. V.; BRANDÃO, I. J.; LOPES, W. P. Ecological restauration in area dominated by Pteridium aquilinum (L.) Kuhn in Caparaó National Park, MG. Revista Árvore, Viçosa, v. 41, n. $1,2017$.

CAPELlESSO, E. S.; SANTOLIN, S. F.; ZANIN, E. M. Banco e chuva de sementes em área de transição florestal no Sul do Brasil. Revista Árvore, Viçosa, v. 39, n. 5, p. 821-829, 2015.

CHADA, S. S.; CAMPELlO, E. F. C.; FARIA, S. M. Sucessão vegetal em uma encosta reflorestada com leguminosas arbóreas em Angra dos Reis, RJ. Revista Árvore, Viçosa, v. 28, n. 6, p. 801-809, 2004.

EMPRESA BRASILEIRA DE PESQUISA AGROPECUÁRIA (EMBRAPA). Sistema brasileiro de classificação de solos. 3. ed. Brasília, 2013. 353p.

HARPER, J. L. Population biology of plants. London: Academic Press, 1977. 892p.

KANIESKI, M. R.; LONGHI, S. J.; ARAUJO, A. C. B. Quantificação da biodiversidade em Floresta Ombrófila Mista por meio de diferentes Índices Alfa. Scientia Forestalis, Piracicaba, v. 38, n. 88, 2010.

MARTINS, S. V. Restauração ecológica de ecossistemas degradados. Viçosa, MG: UFV, 2012. 293p.

MARTINS, S. V.; ALMEIDA, D. P.; FERNANDES, L. V.; RIBEIRO, T. M. Banco de sementes como indicador de restauração de uma área degradada por mineração de caulim em Brás Pires, MG. Revista Árvore, Viçosa, v. 32, n. 6, p. 1081-1088, 2008.

MARTINS, S. V.; RODRIGUES R. R.; GANDOLFI, S.; CALEGARI, L. Sucessão ecológica: fundamentos e aplicações na restauração de ecossistemas florestais. In: Martins SV, editor. Ecologia de florestas tropicais do Brasil. 2. ed. Viçosa: Editora UFV; 2012.

MIRANDA NETO, A.; KUNZ, S. H.; MARTINS, S. V. SILVA, K. A.; DA SILVA, D. A. Transposição do banco de sementes do solo como metodologia de restauração florestal de pastagem abandonada em Viçosa, MG. Revista Árvore, Viçosa, v. 34, n. 6, p. 1035-1043, 2010.

MIRANDA NETO, A.; MARTINS, S. V.; SILVA, K. A.; GLERIANI, J. M. Banco de sementes do solo e serapilheira acumulada em floresta restaurada. Revista Árvore, Viçosa, v. 38, n. 4, p. 609-620, 2014.

MIRANDA NETO, A.; MARTINS, S. V.; SILVA, K. A.; LOPES, A. T.; DEMOLINARI, R. A. Banco de Sementes em Mina de Bauxita Restaurada no Sudeste do Brasil. Floresta e Ambiente, Seropédica, v. $24,2017$.

OKSANEN, J. F.; BLANCHET, G.; FRIENDLY, M.; KINDT, R.; LEGENDRE, P.; McGLINN, D.; MINCHIN, P. R.; O’HARA, R. B.; SIMPSON, G. L.; SOLYMOS, P.; STEVENS, M. H. H.; SZOECS, E.; WAGNER, H.Vegan: community ecology package. R package version, v. 1, p. 8-8, 2016.

PEREIRA, I. M.; AlVAREnGA, A. P.; BOTElHO, S. A. Banco de sementes do solo, como subsídio à recomposição de mata ciliar. Floresta, Curitiba, v. 40, n. 4, p. 721-730, 2010.

R DEVELOPMENT CORE TEAM. R: A language and environment for statistical computing. R Foundation for Statistical Computing. Disponível em: 〈http://www.R-project.org>. Acesso em: 22 dez. 2016.

RIBEIRO, T. O.; BAKKE, I. A.; SOUTO, P. C.; BAKKE, O. A.; LUCENA, D. S. Diversidade do banco de sementes em diferentes áreas de Caatinga manejadas no semiárido da Paraíba, Brasil. Ciência Florestal, Santa Maria, v. 27, n. 1, p. 203-213, 2017.

RECH, C. C. C.; SILVA, A. C.; HIGUCHI, P.; SCHIMALSKI, M. B.; PSCHEIDT, F.; SCHMIDT, A. B.; ANSOLIN, R. D.; BENTO, M. A.; MISSIO, F. F.; LOEBENS, R. Avaliação da restauração florestal de uma APP degradada em Santa Catarina. Floresta e Ambiente, Seropédica, v. 22, n. 2, p. 194-203, 2015. 
RODRIGUES, B. D.; MARTINS, S. V.; LEITE, H. G. Avaliação do potencial da transposição da serapilheira e do banco de sementes do solo para restauração florestal em áreas degradadas. Revista Árvore, Viçosa, v. 34, n. 1, p. 65-73, 2010.

RODRIGUES, R. R.; GANDOLFI, S. Restauração de florestas tropicais: subsídios para uma definição metodológica e indicadores de avaliação e monitoramento. In: DIAS, L. E.; MELLO. J. W. (Eds.). Recuperação de áreas degradadas. Viçosa: UFV, SOBRADE, 1998. p. 203-215.

SCHORN, L. A.; FENIlli, T. A. B.; KRÜGER, A.; PEllenS, G. C.; BUDAG, J. J. NADOLNY, M. C. Composição do banco de sementes no solo em áreas de preservação permanente sob diferentes tipos de cobertura. Floresta, Curitiba, v. 43, n. 1, p. 49-58, 2013.

ZIMMERMAN, J. K.; JOHN B. PASCARELLA, J. B.; AIDE, M. T. Barriers to forest regeneration in abandoned pasture in Puerto Rico. Restoration Ecology, Washington, v. 8, n. 4, p. 350-360, 2000. 